\section{Instagram: análise crítica das postagens jornalísticas através da Teoria da Relevância}

Instagram: critical analysis of news coverage posts through the Relevance Theory

Tiago Lessas José de ALMEIDA (UFPE)

lessas.tiago@gmail.co

Recebido em: 31 de ago. de 2020. Aceito em: 26 de nov. de 2020.

\title{
00000000000
}

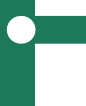

ALMEIDA, Tiago Lessas José de.

Instagram: análise crítica das

postagens jornalísticas através da

Teoria da Relevância. Entrepalavras

Fortaleza, v. 11, n. 2, e2045, p. 1-20, maio-ago./2021. DOI: 10.22168/2237-

6321-22045.

Resumo: A partir da Teoria da Relevância e da Teoria Social do Discurso, este artigo analisa as estruturas enunciativas de publicações jornalísticas no Instagram e as estratégias de otimização textual. O objeto de estudo analisado diz respeito às postagens de algumas das agências de notícias brasileiras quando do pronunciamento oficial do presidente Jair Bolsonaro na noite de 31 de março de 2020. Para este estudo, foram selecionadas as postagens sobre o referido evento de três agências de notícias de grande visibilidade, de modo que podemos perceber as formas estratégicas de construção textual a partir de uma análise pragmático-crítica. Com base nessa análise, podemos notar que as postagens jornalísticas no Instagram tendem a hiper-otimizar o processo de compreensão, prejudicando os aspectos de reflexão crítica dos leitores.

Palavras-chave: Compreensão textual. Instagram. Teoria da Relevância. Análise do Discurso. 
V. $11(2)$

1-20

maio-ago

2021

Abstract: Based on the Relevance Theory and the Social Theory of Discourse, this article analyzes the enunciative structures of journalistic publications on Instagram and its ostensive-inferential strategies. The object of study analyzed concerns the posts of some of the Brazilian news agencies at the time of president Jair Bolsonaro's official pronouncement on the night of March 31, 2020. Three publications were selected from three Brazilian news agencies of great visibility when they covered the event. The study shows that we can notice the strategic forms of textual construction from a critical-pragmatic analysis. Furthermore, we can see that Instagram news coverage publications tend to hyper-optimize the comprehension process, jeopardizing readers' critical reflections.

Keywords: Reading. Instagram. Relevance Theory. Critical Discourse Analysis.

\section{Introdução}

Em tempos de revolução industrial 4.0, internet das coisas, big data e armazenamento de dados em nuvens, a veiculação das informações em plataformas se tornou uma questão crucial no campo dos estudos da cognição e do discurso (XAVIER, 2013a, 2013b; RENÓ, 2019; BUZATO, 2007). A política do século XXI parece ter percebido a relevância e o poder discursivo das interações digitais na tomada de decisões governamentais e até mesmo nos possíveis resultados das eleições. O historiador Yuval N. Harari (2018) atribui ao uso das tecnologias da comunicação e das redes sociais o avanço de discursos separatistas e eleições de figuras contraditórias, como Donald Trump, à presidência dos Estados Unidos.

Assim, o presente artigo visa analisar algumas publicações jornalísticas na rede social Instagram, com sua atual configuração e modus operandi, de forma a compreender como as estruturas enunciativas das publicações de algumas das principais agências de notícias do Brasil são utilizadas como estratégias para o direcionamento inferencial dos fatos noticiados. É importante destacar que o termo estrutura enunciativa engloba a organização estética, gráfica e os recursos de operação da rede social em questão. Compreendemos que tais componentes fazem parte de todo o processo de construção do discurso dos atores sociais, criando elementos ostensivos de pistas inferenciais¹ (SPERBER; WILSON, 2005).

Na rede social Instagram, os recursos utilizados pelos perfis de agências de notícias e jornais tradicionais costumam seguir um padrão de configuração textual parecido com os textos publicados em mídias

\footnotetext{
${ }^{1}$ O conceito de elementos ostensivos será mais bem desenvolvido na seção de fundamentação teórica, mas é importante destacar que este se refere à capacidade que os interlocutores têm de otimizarem a compreensão através de recursos linguísticos e gestuais, de forma a direcionar o sentido dos enunciados (SPERBER; WILSON, 2005).
} 
físicas. A publicação (ou post) principal funciona, no geral, como um título, ou legenda, para a matéria principal que estará presente nos comentários abaixo da publicação ou que será direcionada em forma de endereço html. Tais hipertextos como matéria principal tendem a aparecer no corpo do texto citado nos comentários, ou simplesmente são indicados ao leitor como estando localizados na bio em forma de hiperlink. O uso das imagens, nesse tipo de publicação, tende a estabelecer relação discursiva com o fato noticiado e a escrita pauta-se por construções mais objetivas e sentenças curtas.

No entanto, partimos da premissa de que os leitores em redes sociais como o Instagram optam por ter sua leitura da reportagem satisfeita com a legenda da imagem principal da publicação. Afinal, a rede social foi originalmente desenhada como uma plataforma de compartilhamento de imagense, aparentemente, continua exercendoessa função última. Obviamente, mais pesquisas quanto ao comportamento de leitura no Instagram necessitam ser realizadas, por isso, tomamos como parâmetro nossa percepção de usuários e observadores.

As agências de notícias e jornais tradicionais parecem ter compreendido tais formas de uso da rede social e criam publicações simples que satisfazem um tipo de leitura rápida. Vários aspectos justificam isso, especialmente quando notamos a opção de sucessão de postagens por rolagem (especialmente na sua versão para smartphones) e o aspecto dimensional preferível das imagens nas postagens: 1:1, ao invés de 16:9 ou 18:9, que são as dimensões preferíveis em aplicativos leitores de $e$-book, por exemplo.

Com base nisso, o presente artigo tem a seguinte questão central: como o Princípio Cognitivo da Relevância fornece os dispositivos inferenciais teóricos para compreendermos os possíveis efeitos discursivo-cognitivos que algumas publicações jornalísticas no Instagram podem produzir? Evidentemente, o corpus selecionado para essa pesquisa ainda é parte de uma introdução nos estudos do discurso em veículos de redes sociais. Portanto, compreendemos que os resultados aqui obtidos precisam ser expandidos para pesquisas mais abrangentes.

Para responder a essa questão, adotamos como hipótese central que as postagens de notícias de agências e jornais tradicionais

${ }^{2}$ Bio se refere ao espaço localizado logo abaixo da foto de um perfil e é reservado para introdução de informações relevantes para os perfis no Instagram, sendo este atualmente o único local na plataforma onde é possível adicionar textos em hiperlink. 
V. 11 (2)

1-20

maio-ago

2021 na rede social Instagram têm características textuais específicas, estrategicamente construídas para hiper-otimizar o processo inferencial. Se estivermos corretos, essa evidência enunciativa não pode ser considerada apenas como um elemento de produção enunciativa e proposta de leitura em espaços digitais. Na verdade, ela deve estar também associada a um processo de prática social de controle discursivo (van DIJK, 2010; FAIRCLOUGH, 2016).

\section{Teoria da Relevância}

Estudar os aspectos cognitivos da compreensão humana não pode se dar exclusivamente através do código linguístico. Entretanto, compreendemos que, para os fins investigativos nesse estudo, precisamos delimitar nosso campo de investigação ao nível da língua. Essa escolha, apesar de soar arbitrária, tem sua razão na medida em que propomos discutir os efeitos de sentido tangíveis no código linguístico. Obviamente, reconhecemos que o processo inferencial não se dá exclusivamente por esse viés. Não é sem razão que encontramos na Teoria da Relevância (SPERBER; WILSON, 2005) o dispositivo analítico propício para o exercício da análise textual/enunciativa.

\section{A teoria supracitada tem no Princípio Cognitivo da Relevância} sua base epistêmica. Em linhas gerais, esse princípio explica que os interlocutores buscam/produzem estímulos ostensivos que satisfaçam a presunção de inferência, levando em conta o peso relevante que cada estímulo deve ter para suas escolhas de sentido durante a interpretação do enunciado. Nesse caso, o procedimento de compreensão regular que os humanos seguem seria sempre o de exercer menor esforço para computar dados interpretativos, parando o processo de interpretação quando as "expectativas de relevância são satisfeitas" (SPERBER; WILSON, 2005, p. 252).

Segundo essa teoria, é o sujeito produtor do enunciado quem cria inputs (estímulos) ostensivos de tópicos relevantes para o interlocutor realizar a interpretação. O leitor/ouvinte, nesse caso, mensura os inputs enunciativos que parecem mais ou menos relevantes o suficiente para guiá-lo no cômputo inferencial. Podemos dizer que a Teoria da Relevância, nesse caso, é um dispositivo teórico de caráter cognitivo semi-modular que tenta explicar as estratégias de compreensão a partir dos componentes decodificáveis da comunicação humana. 
A proposta da Teoria da Relevância é fornecer um "modelo inferencial", no qual um sujeito comunicador "fornece evidência de sua intenção de comunicar um certo sentido, que é inferido pela audiência com base na evidência fornecida" (SPERBER; WILSON, 2005, p. 221). Esse modelo inferencial tem raízes epistêmicas cognitivas na hipótese central de que todos os enunciados produzidos são estruturados em expectativas de relevância, isto é, dispositivos pragmático-textuais que fornecem pistas e geram previsibilidade "para guiar o ouvinte na direção do significado do falante3" (SPERBER; WILSON, 2005, p. 222).

A relevância, segundo a teoria, é "uma característica básica da cognição humana" (SPERBER; WILSON, 2005, p. 223), de modo que o input relevante pode se configurar enquanto qualquer aspecto enunciativo que ajude o leitor/ouvinte a extrair conclusões, responder a uma determinada questão, aceitar uma ideia, confirmar suposições ou corrigir posicionamentos. Em outras palavras, o sujeito ancora seu cômputo inferencial entre indícios mais ou menos relevantes que o guiem na direção do sentido ótimo ou do proposto pelo interlocutor. O resultado bem-sucedido da relação entre os inputs relevantes estabelecidos pelo interlocutor e o cálculo inferencial do leitor/ouvinte é chamado de "efeito cognitivo positivo" (SPERBER; WILSON, 2005, p. 223).

Sperber e Wilson (2005) não desconsideram o fato de que os sujeitos têm condições autônomas de determinar suas próprias condições de verdade subjetivamente, mesmo quando essas conclusões são descoladas dos inputs otimizados no enunciado. Entretanto, a noção de efeito cognitivo positivo no contexto epistemológico da teoria se refere ao acesso cognitivo realizado com base em evidências enunciativas, ao invés de posicionamentos individuais pragmaticamente inconcebíveis.

Por isso, é importante que se esclareça que "um input é RELEVANTE para um indivíduo quando, e somente quando, seu processamento produz tais efeitos cognitivos positivos" (SPERBER; WILSON, 2005, p. 224, grifos nossos). Ou seja, temos que levar em consideração que os indivíduos fazem cálculos mais ou menos objetivos; e, mesmo que consideremos as particularidades do contexto enunciativo, nossa análise nunca poderá determinar com máxima precisão quais conclusões fazem os indivíduos.

\footnotetext{
3 Ou autores usam os termos falantes e ouvintes constantemente porque seus exemplos de análises são essencialmente enunciados orais de diálogos. Entretanto, a Teoria da Relevância se aplica também aos textos escritos e, por isso, fazemos por vezes o uso do termo interlocutores no âmbito deste artigo.
} 
V. 11 (2)

1-20 maio-ago 2021
O que podemos determinar, no entanto, é o efeito de sentido e os processos cognitivos que temos à disposição. A relevância tem como índice indicador o esforço de processamento. Segundo Sperber e Wilson (2005, p. 225), "quanto maior for o esforço requerido de percepção, de memória e de inferência, menor será a recompensa pelo processamento do input e, por isso, um menor merecimento de atenção". Os autores argumentam que podemos explicar a inferenciação a partir de estruturas enunciativas que exigem pouco esforço cognitivo-processual do sujeito.

Por exemplo, em ambientes de leitura rápida (nosso caso, postagens on-line), os inputs relevantes podem estar associados a fatores que direcionam a atenção do leitor, exigindo o mínimo de atenção possível. Nesse caso, "quanto maior o ESFORÇO DE PROCESSAMENTO requerido, menos relevante será o input") (SPERBER; WILSON, 2005, p. 225). O esforço de processamento está, assim, diretamente acoplado aos fatores tempo e atenção, sendo esses os fatores mais bem otimizados em redes sociais, como o Instagram4.

De acordo com esse princípio cognitivo, o sujeito faz o cômputo seguindo duas possibilidades de inferenciação: sentido default e ad hoc (SPERBER; WILSON, 2005). No primeiro, o conceito é recuperado pelo termo ou léxico. Ou seja, o sentido default está associado ao significado de base mais genérica, sendo mais facilmente decodificável a partir do conhecimento linguístico e enciclopédico. Quanto ao segundo, o sentido é recuperado pragmaticamente pelo contexto, pala situação enunciativa. Desse modo, a interpretação ad hoc depende de um cálculo inferencial mais profundo e, possivelmente, descolado do seu sentido default. Compreender a função desses dispositivos cognitivos pode nos ajudar a estabelecer relações de força de relevância no que se refere ao cômputo inferencial.

\section{Teoria Social do Discurso}

Compreender os eventos enunciativos sob uma perspectiva da relevância é se perguntar quais efeitos de sentido subjazem aos enunciados, pois as interações comunicativas pressupõem não apenas

\footnotetext{
${ }_{4}^{4}$ As postagens tipo Stories no Instagram têm, atualmente, limite de 15 segundos e parecem servir como recurso fundamental no formato de vídeos que consigam otimizar e condensar informações. O recurso Stories ainda é visualmente identificado com traços no topo da tela do aplicativo, indicando a quantidade de vídeos em 15 segundos produzidos naquele dia por um determinado perfil. Recentemente, aplicativos como o Inshot e Hyperlapse (sendo este último um lançamento do próprio Instagram) foram desenvolvidos para ajudar os usuários a produzirem mais profissionalmente seus vídeos, otimizando tempo e atenção das informações.
} 
relações inferenciais, mas também práticas discursivas. Enquanto a Teoria da Relevância se preocupa em dar conta de explicar os processos cognitivos na esfera da inferenciação, é preciso pensarmos em como tais estratégias cognitivas estão encapsuladas na esfera da estruturação discursiva.

A esse respeito, a Análise Crítica do Discurso (FAIRCLOUGH, 2016) oferece uma abordagem teórica que nos ajuda a compreender os aspectos sociais da produção dos enunciados. A Análise Crítica do Discurso, também denominada como Teoria Social do Discurso (FAIRCLOUGH, 2016), se preocupa com as relações de poder e controle social através das práticas sociais mediadas por textos. Esse conceito é importante para explicarmos os efeitos de sentido dos enunciados na medida em que reconhecemos o papel de interface do texto entre a cognição e a sociedade.

Segundo Fairclough (2016, p. 110), a estrutura textual "diz respeito à 'arquitetura' dos textos e especificamente a aspectos superiores de planejamento de diferentes tipos de texto". Por isso, compreendemos que, ao analisarmos publicações on-line de agências de notícia em redes sociais, se faz necessário levar em conta a relação entre os sentidos potenciais produzidos e a construção de enunciados estrategicamente estruturada.

Fairclough (2016) identifica nas formas de organização enunciativas certas tendências ${ }^{5}$ que implicam no uso dos textos para controle discursivo. Uma dessas tendências se refere à "tecnologização discursiva" (FAIRCLOUGH, 2016, p. 275), a qual compreende os usos de técnicas de linguagem enquanto atividade de sofisticação para práticas discursivas de poder. As formas de enunciação digital, especialmente em redes sociais, têm se apresentado a partir de estratégias específicas para orientar a interpretação dos leitores. Os usos enunciativos simples, concisos e hipertextualizados podem confirmar tal tendência em práticas comunicativas. Dessa forma, nossa hipótese central de que os usos das publicações no Instagram por veículos de notícias são estratégias de hiper-otimização inferencial se caracteriza, em última instância, como uma tendência da tecnologização do discurso próprio da esfera das redes sociais.

\footnotetext{
${ }^{5} \mathrm{O}$ termo tendência é utilizado por Fairclough (2016) para se referir à forma como o autor percebe os usos discursivos da linguagem na prática social. Em outras palavras, as tendências são as categorias de análise de que ele lança mão para analisar a produção textual numa determinada prática social.
} 
V. 11 (2)

1-20

maio-ago

2021

Com essas bases teóricas delineadas, desenvolvemos uma análise de três postagens no Instagram das seguintes agências de notícia: (1) Diário de Pernambuco, (2) Estadão e (3) Mídia Ninja. Esta análise pode nos ajudar a perceber como o Princípio Cognitivo de Relevância é subjacente às estruturas enunciativas de forma estratégica nas publicações no Instagram. Desse modo, desenvolvemos uma análise com base nas implicaturas cognitivamente otimizadas, de forma a percebermos como tais publicações, enquanto exemplos de construção textual jornalística na referida rede social, podem esboçar uma prática discursiva específica.

\section{Análise das publicações}

Em pronunciamento oficial exibido em 31 de março de 2020 a respeito da pandemia de COVID-19, o presidente Jair Bolsonaro afirma haver uma necessidade tangível da retomada das atividades econômicas normais. Esse pronunciamento é claramente menos impositivo que o anterior divulgado, de 24 de março do mesmo ano, em que o presidente usa termos pouco científicos ao se referir aos sintomas da doença.

No pronunciamento de 31 de março, Bolsonaro aponta algumas ações do governo no controle do nível de infecção da COVID-19. O presidente ainda reafirma seu discurso de retorno aos postos de trabalho por parte da população e tenta convencer o ouvinte de sua preocupação em relação aos efeitos colaterais e econômicos da pandemia no país. É evidente a tentativa do presidente de amenizar as críticas do pronunciamento anterior, de 24 de março, ao passo que reitera sua posição de que a pandemia não justifica as medidas tomadas pelo seu Ministério da Saúde ${ }^{6}$. Como vamos observar nas análises a seguir, as referidas agências de notícias publicaram no Instagram alguns destaques do pronunciamento.

Veículo de notícia: Diário de Pernambuco

(1) Legenda principal da publicação: Bolsonaro muda o tom e afirma "estamos diante do maior desafio da nossa geração" .

\footnotetext{
${ }^{6}$ Todas essas questões são verificáveis nos pronunciamentos oficiais do presidente, disponíveis no canal oficial Palácio do Planalto, no YouTube através do link <https://www.youtube.com/ user/PalaciodoPlanalto>.
}

${ }^{7}$ Postagem do dia 31 de março de 2020 no perfil do Instagram do jornal Diário de Pernambuco 
O primeiro texto analisado aqui é um post do jornal Diário de Pernambuco. Na publicação acima citada, o texto que aparece em posição de legenda na postagem está posicionado no terço inferior da imagem do presidente Jair Bolsonaro (ver link para a publicação). O destaque é dado à retórica da fala do presidente e a citação direta deste é colocada sintaticamente na segunda posição de uma oração coordenada sindética aditiva, categorizada com o uso da partícula "e". Isso implica em orientar o leitor a focar sua atenção ao termo "tom" e associá-lo à afirmação do chefe do executivo de que haveria um grande desafio posto diante da população.

É fundamental que se compreenda que esse o processo inferencial depende de elementos ostensivos, de acordo com o Princípio Cognitivo da Relevância. Nesse caso, em que analisamos o enunciado, os inputs ostensivos podem estar associados à escolha léxica, pois "mudar o tom" tem implicaturas de modalização da linguagem. Por sua vez, essa escolha de palavras chama atenção pelo fato de se contrapor ao enunciado entre aspas, claramente uma indicação de que se trata da fala do presidente Bolsonaro.

O foco ostensivo de atenção da reportagem é a afirmação de "desafio" imposto pela pandemia do novo coronavírus. No entanto, essa parece ser a afirmação menos discursivamente relevante no contexto do pronunciamento como um todo. Ao escolher essa citação direta como destaque, o periódico sugere ao leitor concentrar sua leitura na primeira oração, a qual reflete muito mais uma opinião do que uma descrição.

O input ostensivo na primeira oração é o termo "tom", o qual sugere algumas interpretações possíveis. A interpretação default (1a) estaria associada à variação de intensidade, tanto no campo das artes plásticas, quanto dos estudos do som (FERREIRA, 2020). A segunda interpretação ( $1 \mathrm{~b}$ ) poderia estar associada à fala, devido ao uso recorrente de expressões que aludem ao tom da voz em contextos de enunciação. $\mathrm{O}$ uso do termo, nesse caso específico, parece se vincular à interpretação (1b), ao passo em que explora outras possibilidades de implicabilidade. O uso da palavra "tom", na reportagem, não indica apenas a ideia de baixar a voz, mas pode se referir ao ato de acionar modulações menos agressivas.

sobre o pronunciamento do presidente Jair Bolsonaro, exibido no mesmo dia. Link para publicação no Instagram: <https://www.instagram.com/p/B-asKN4DaYq/?hl=pt-br >. Acesso em: 1 abr. 2020. 
V. 11 (2)

1-20

maio-ago

2021

É possível concluirmos que o enunciado implica uma interpretação ad hoc: "mudar o tom" (1c) é relativizar a opinião anterior. Isto é, o enunciado pede que o leitor acione conhecimentos enciclopédicos que fazem referência ao pronunciamento anterior. Nesse sentido, compreendemos que os eventos são componentes armazenados mentalmente que se constituem na representação discursiva individual de eventos (AZEVEDO, 2008); ou seja, os sujeitos criam acessos representacionais diversos sobre os mesmos eventos. Por isso, o sentido ad hoc do termo "mudar" é um input ostensivo nesse enunciado, pois seu uso estratégico em detrimento de "baixar" cria expectativas de relevância ótima para a interpretação (1c).

Em termos visuais, é importante levar em consideração como a imagem é parte essencial do enunciado e pode se configurar como dispositivo relevante de implicaturas ${ }^{8}$. O uso da imagem de perfil (ver link) do presidente implica uma escolha não apenas por um ângulo aleatório ${ }^{9}$, mas parece exercer um senso enunciativo de interlocução com outros que não necessariamente o leitor. O direcionamento do olhar do falante preferido pela reportagem, em detrimento de um enquadramento central típico de pronunciamentos oficiais, atua como elemento não-verbal ostensivo em conjunto com o enunciado.

Pelos nossos estudos iniciais, percebemos que legendas em postagens de veículos de comunicação no Instagram são tentativas de sintetização dos aspectos relevantes de fatos reportados em outras plataformas. Se esse é o caso, há que se levar em conta os possíveis efeitos de sentidos que os direcionamentos de interpretações otimizadas teriam nos sujeitos leitores. Ao fazer uso de léxicos como "tom" e "mudar", a postagem constrói efeitos de sentidos que dialogam com situações comunicativas exteriores. "Mudar" pode servir como dispositivo linguístico-cognitivo de acesso ao conceito de inversão ou de escolha em direção contrária. Uma vez que esse pode ser o sentido pretendido com base no enunciado, o leitor pode ser direcionado a fazer o seguinte cálculo interpretativo (c1): o presidente adota um novo posicionamento e encara a pandemia como um problema grave. Esse parece ser o caminho ótimo hiper-otimizado pela publicação, ou seja, nesse processo enunciativo há elementos textuais que indicam um sentido interpretativo.

\footnotetext{
${ }^{8}$ Implicatura se refere ao sentido intencional possivelmente interpretado a partir do contexto enunciativo (SPERBER; WILSON, 2005).

9 Na imagem em questão, a publicação opta por uma foto de perfil de Bolsonaro, como se pode observar no link indicado na nota de rodapé.
} 
Porém, se o leitor aplica maior esforço cognitivo e relaciona elementos ostensivos não-verbais, levando em consideração seu conhecimento enciclopédico e episódico, acessando textos externos, pode-se concluir um segundo cálculo interpretativo (c2): o presidente é forçado a mudar sua posição discursiva em relação à pandemia, provavelmente devido a pressões públicas diante de suas afirmações anteriores.

A partir da estrutura enunciativa, o post revela aspectos inferenciais, especialmente através do uso de elementos ostensivos, que sugerem um sentido particular do Diário de Pernambuco em relação ao proferimento como um todo. Tal sentido construído no post, seja a conclusão (c1), seja a (c2), não é suficiente para englobar o todo enunciativo do pronunciamento oficial e funciona, portanto, como elemento hiper-ostensivo, mais do que descritivo.

$\mathrm{Na}$ análise acima, é possível notar que a Teoria da Relevância pode ajudar a explicar como algumas postagens no Instagram se valem de estruturas enunciativas que otimizam ou facilitam a compreensão num direcionamento específico. Percebemos que a otimização hiper-ostensiva parece ser usada como um possível posicionamento político e ideológico da agência. Esse caráter discursivo que subjaz aos elementos pragmáticocognitivos acessados através do Princípio Cognitivo da Relevância demonstra que o sujeito usuário está inserido em práticas discursivas de controle inferencial para produção de significados potenciais (FAIRCLOUGH, 2016).

Evidentemente, a representação cognitiva de episódios é notavelmente indissolúvel da prática social, de forma que qualquer enunciado é construído na interface discurso-sociedade, sendo também subjetivado pelos sujeitos (AZEVEDO, 2008). No entanto, nos parece particularmente significativo o fato de esse processo ser fortemente otimizado em publicações no Instagram, pois, além de promover recortes limitados de episódios noticiados, é possível que o direcionamento inferencial esteja contingenciado tanto pela estrutura enunciativa da plataforma, como pelas relações de controle discursivo. Sendo esse o caso, tais publicações oferecem pouco espaço para produções de sentidos mais criticamente construídas. 
V. 11 (2)

1-20

maio-ago

2021

Veículo de notícia: Estadão

(2)Legenda principal da publicação: Bolsonaro volta a usar OMS para 'criticar destruição de empregos' e é alvo de panelaço. ${ }^{10}$

O destaque da postagem publicada no perfil do Instagram do jornal Estadão apresenta duas questões: 1. o presidente Bolsonaro critica a política de enfrentamento à pandemia de COVID-19 e 2. o presidente recebe críticas da população em forma de protesto. Como observado na postagem anterior (Diário de Pernambuco), a construção sintática da postagem também faz uso de uma oração coordenada sindética aditiva, categorizada com o uso da partícula "e".

Esse é um fator relevante para a orientação interpretativa do leitor, pois estabelece a existência de dois fatos centrais na notícia, o que poderia criar um efeito enunciativo de concisão da reportagem em apenas dois aspectos básicos. Para as condições de comportamento de leitura em redes sociais, essa formação sintática pode ser conveniente no sentido de otimizar uma proposta de complexidade ao texto. No entanto, essa sensação artificial de leitura mais detalhada não se concretiza diante do óbvio curto espaço textual típico de publicações em Instagram.

Nesse respeito, seria incoerente supormos que, ao se fazer uso econômico de palavras, haveria a possibilidade de se alcançar o sentido oposto "do que se pretendia transmitir" (SPERBER; WILSON, 2005, p. 246). Ou seja, a textualidade econômica no layout da postagem otimiza a compreensão dos leitores no sentido de interpretarem publicações de veículos de notícias mais próximas de implicaturas hiper-otimizadas do que interpretações metafóricas, default ou menos óbvias.

No enunciado em questão, temos a primeira oração: "Bolsonaro volta a usar OMS para "criticar destruição de empregos"'. O uso do léxico verbal "volta" cria algumas explicaturas acessíveis ao leitor. Primeiramente, "volta" pode ser interpretado a partir de dois sentidos default: (1a) retornar ou vir novamente a algum lugar e (1b) restituir ou entregar novamente algo a alguém (FERREIRA, 2020). Entretanto, diante do uso da locução verbal em que o verbo está inserido ("volta

\footnotetext{
${ }^{10}$ Postagem do dia 31 de março de 2020 no perfil do Instagram do jornal Estadão sobre o pronunciamento do presidente Jair Bolsonaro, exibido no mesmo dia. Link para publicação no Instagram: <https://www.instagram.com/p/B-as8qZDwmZ/?hl=pt-br>. Acesso em: 1 abr. 2020.
} 
a usar"), "volta" incorpora a interpretação ad hoc (2a) de repetir ou rescindir em uma mesma ação.

Quanto à segunda oração da legenda na postagem ("e é alvo de panelaço"), percebemos que esta funciona como um dispositivo ostensivo de acesso a conhecimento enciclopédico. Os componentes enciclopédicos funcionam como elementos inferenciais que indicam ao sujeito o caminho mais rápido a seguir no cômputo interpretativo. Em função desses dispositivos enciclopédicos, os leitores/ouvintes podem restringir os sentidos aplicados às palavras e fazer escolhas relevantes e mais otimizadas entre os sentidos ad hoc.

No exemplo em questão, temos a palavra "panelaço", que parece indicar em seu sentido default (3a) o ato de bater panelas em sinal de protesto. No entanto, para essa interpretação particular, o sujeito deverá aplicar seu conjunto de conhecimento enciclopédico para reconhecer a denotação ad hoc (3b): protestos realizados às janelas de condomínios ao som de batidas de panelas durante o período de quarentena da pandemia de COVID-19.

Quanto ao estímulo de relevância ótima, o termo "panelaço" parece funcionar como fator de recontextualização enunciativa, isto é, adiciona-se contexto a um acontecimento reportado para efeitos de associação causa-e-efeito. Dizemos isso por compreendermos que o ato panelaço é um elemento externo ao proferimento. Dessa forma, o fato de a publicação condensar dois eventos em uma única postagem esboça uma estratégia discursiva direcionada à crítica.

Essa estratégia parece ressignificar o sentido geral do pronunciamento, pois, além de informar um fato, a legenda associa enunciativamente a fala do presidente a sua repercussão, atribuindo à primeira uma implicatura negativa do ponto de vista político. Assim, observamos formas estratégicas de tecnologização discursiva no uso ostensivo de elementos linguístico-discursivos.

Portanto, nos parece importante perceber como o Princípio Cognitivo da Relevância pode ser identificado enquanto subjacente às estratégias de hiper-otimização, o que, por sua vez, cria implicações para o processo de compreensão. Ou seja, às vezes a super simplificação no texto se torna um elemento enunciativo-discursivo, e não apenas um elemento estético. 
V. 11 (2)

1-20

maio-ago

2021

Veículo de notícia: Mídia Ninja

(3) Legenda principal da publicação: CHECAMOS: O que é fato, ficção e contradição no quarto pronunciamento de Bolsonaro sobre o coronavírus. ${ }^{11}$

A publicação postada no perfil da agência Mídia Ninja tem uma característica peculiar que foge às demais publicações selecionadas. A primeira palavra que aparece na ordem vertical de cima para baixo é "checamos". Apesar de compreendermos que, do ponto de vista do Princípio Cognitivo da Relevância, essa palavra esteja gráfica e visualmente colocada em segundo plano - pois seu tamanho de fonte é comparativamente menor do que a sentença principal -, ainda podemos argumentar que ela incorpora efeitos cognitivos mais ou menos ostensivos. É natural que o leitor seja levado a ter em mente este termo durante a leitura da postagem. Inferencialmente, o léxico "checar" denota os sentidos default (1a) verificar e (1b) investigar (FERREIRA, 2020). A diferença semântica aplicada à palavra vai em muito depender do contexto comunicativo.

Em situações comunicativas diárias, a implicatura default (1a) é mais facilmente pressuposta. No entanto, devido às pistas comunicativas expostas na publicação acima - isto é, o tema abordado, o ator social noticiado, o gênero da esfera da notícia e as estratégias linguísticas empregadas -, a implicatura resultante da relevância ótima denota o sentido (1b). Assim, o leitor parece ser orientado a articular acessos cognitivos que o remetem a situações de investigações policiais. Esse estímulo indica possibilidades de redução de esforço cognitivo ao se computar as informações que irão se seguir, pois o leitor é inicialmente incentivado a estabelecer relações de sentidos do campo policial/ investigativo com as informações dadas pela postagem.

Podemos atentar a uma estratégia pretensamente não ostensiva nesta publicação. Segundo a Teoria da Relevância, um estímulo alcança sua presunção ótima quando somos levados a parar o cômputo inferencial uma vez que nossas expectativas de compreensão forem satisfeitas. Se observarmos o posicionamento gráfico da palavra "checamos" (ver link para a publicação), conseguimos perceber que, apesar de não ter nem

\footnotetext{
${ }^{11}$ Postagem do dia 31 de março de 2020 no perfil do Instagram da agência de notícias Mídia Ninja sobre o pronunciamento do presidente Jair Bolsonaro, exibido no mesmo dia. Link para publicação no Instagram: <https://www.instagram.com/p/B-cHERmJp3H/>. Acesso em: 1 abr. 2020.
} 
o mesmo tamanho de fonte, nem o mesmo destaque que o restante das informações escritas, ela ainda se apresenta em letras grafadas em caixa alta. Além do mais, o fato de essa palavra ser utilizada no topo esquerdo da publicação funciona como mais um elemento ostensivoinferencial de destaque na postagem. Há um efeito de tensão inferencial que fornece ao leitor base para dar o peso suficientemente provável ao sentido (1b) e, ao mesmo tempo, a publicação parece criar um efeito de autonomia de interpretação. Ao se definir três condições de análise ("fato, ficção e contradição"), o leitor é sistematicamente convidado a tirar conclusões.

Nesse respeito, das três publicações que analisamos aqui, a postagem da Mídia Ninja é a única que, além de otimizar o espaço dimensional proporcionado pelo formato de publicações no Instagram, evita se resumir a apenas uma imagem. Na mesma publicação, encontramos mais outras cinco imagens que dão continuidade à notícia em destaque.

Evidentemente, nãoépossível afirmarmos que nessa publicação temos evidências de propostas de leituras mais profundas a respeito dos fatos noticiados. No entanto, fica claro que há uma tentativa de expansão dos processos de leitura para além da experiência de produção textual típica de jornais tradicionais no Instagram.

Segundo Fairclough (2016), a dinâmica sociodiscursiva é característica essencial dos processos de distribuição e veiculação de textos. O processo de construção de narrativas se dá através de contingência diversas, que, além de produzirem efeitos enunciativos de sentidos, evidenciam posicionamentos e tentativas de controle pelo poder do discurso.

Não obstante, é preciso ressaltar que uma questão não fica muito clara em primeira instância (a não ser pelo uso da marca d'água no canto superior esquerdo da imagem). A postagem publicada pela Mídia Ninja se trata, na verdade, de uma seleção dos principais tópicos investigados pela agência de fact-checking ${ }^{12}$ Aos Fatos, publicado em sua página oficial através do endereço eletrônico http://aosfatos.org.

\footnotetext{
${ }^{12}$ Fact-checking se refere à prática de investigação jornalística de checagem de fatos divulgados na internet como supostamente verdadeiros. A prática utiliza ferramentas digitais e físicas para buscar informações que corroboram ou refutam informações através de fontes confiáveis e visa evitar a propagação de Fake News (AOS FATOS, 2020?). A agência Aos Fatos disponibiliza mais informações a esse respeito: <https://www.aosfatos.org/checagem-de-fatos-ou-factchecking/>. Acesso em 14 abr. 2020.
} 
V. 11 (2)

1-20

maio-ago

2021
Esse input visual funciona como um dispositivo não hiperotimizado que oferece ao leitor acesso a um conhecimento mais vasto quanto às discussões sobre Fake News ${ }^{13}$. Todavia, esse um estímulo ostensivo de menor peso de relevância parece estar associado a outro input linguístico já mencionado acima. Assim, o cômputo inferencial ótimo pressuposto visa satisfazer a interpretação geral de que inverdades/ imprecisões na fala do presidente são coisas recorrentes. Tal conclusão é ostensivamente reforçada pelo uso da palavra "quarto", pois seu significado default de (1a) numeral pode ser rapidamente descartado em virtude do sentido ad hoc de (1b) repetição.

É digno de nota as estratégias de textualização nessa postagem da Mídia Ninja, pois, além de promover uma leitura mais crítica, ainda observamos a existência de seis imagens que constituem a postagem. A agência de notícias Mídia Ninja não tem a intenção apenas de apresentar fatos. Ao propor-se a apresentar resultados de verificações de informações, esta produz efeitos de sentidos contra-hegemônicos. O evento comunicativo é utilizado como ferramenta de análise discursiva, que visa reposicionar o ator social presidente sob uma ótica discursiva negativa. Como Fairclough (2016, p. 98) observa, as "palavras, a prática política e a ideológica não são independentes", pois se constituem nas relações e lutas de poder.

Como pudemos observar até agora, as publicações de agências de notícias em perfil de Instagram exibem características enunciativas particulares. Além do espaço gráfico possibilitado (ou delimitado) visualmente pela plataforma, conseguimos observar que as construções textuais parecem seguir um determinado padrão enunciativo-textual, exibindo componentes sintáticos semelhantes. No entanto, o que parece chamar a atenção, do ponto de vista hermenêutico, é o fato de tais publicações evidenciarem construções cognitivas de relevância ótima facilmente acessíveis, que otimizam consideravelmente o processo de inferência.

Dessa forma, o sujeito leitor tem um arcabouço de estímulos relevantes que sinalizam ostensivamente qual direção interpretativa seguir. Por definição, os estímulos ótimos são componentes enunciativos constitutivos da linguagem. O que as publicações jornalísticas no Instagram parecem fazer é hiper-otimizar esse processo, reduzindo o campo inferencial na direção de compreensão pressuposta pela

${ }^{13} \mathrm{O}$ termo Fake News se refere à prática de divulgação de notícias falsas ou falsificadas, geralmente motivadas por objetivos políticos e com o intuito de promover desinformação (MELLO, 2020). 
agência gerenciadora do perfil. Ou seja, o leitor tem uma limitação de interpretação contingenciada pelas evidências ostensivas. Esse tipo de implicatura não é em si problemática, nem questionável. Na verdade, estratégias assim são mais fortemente utilizadas em campanhas publicitárias e textos informativos. E essa é uma questão importante para nosso argumento central.

As publicações jornalísticas no Instagram não são simplesmente, na maioria dos casos, retextualizações de notícias em veículos mais formais. Elas se valem de efeitos de sentido estratégicos que facilitam a compreensão a ponto de não oferecer práticas de leitura mais abrangentes. Exceto pelas tentativas de estruturação enunciativa observada no perfil da Mídia Ninja, o gênero post de Instagram parece se apresentar sob uma organização convencionalizada, especialmente em perfis de veículos de notícias tradicionais. Esses esforços textuais são evidência de formas de tecnologização do discurso (FAIRCLOUGH, 2016), as quais extrapolam as intenções retóricas e se apresentam enquanto aspectos de controle sociodiscursivo.

\section{Considerações finais}

As redes sociais, enquanto práticas discursivo-sociais, esboçam e produzem relações de poder e lutas hegemônicas através da construção textual. Essa característica fica ainda mais evidente através da temática selecionada para esta pesquisa. Quando analisamos o pronunciamento do presidente Jair Bolsonaro a respeito das medidas de isolamento social, percebemos um posicionamento discursivo contrário à proposta delineada pelo Ministério da Saúde, pois o impacto econômico, na visão do presidente, é um fato tangível, imediato e possivelmente irreversível. Ridicularizar a crise sanitária e menosprezar as mortes da população idosa não são argumentos, são estratégias retóricas de controle discursivo do presidente, e deixa claro o fraco plano de governo no qual sua administração se baseia.

Doravante, acreditamos que o leitor, enquanto ator social, deve desenvolver a capacidade da hermenêutica crítica, de forma que não se limite a leituras superficiais sobre questões fundamentais, como as tomadas de decisões políticas. Confiar nas plataformas digitais de redes sociais como única fonte de informação, sem recorrer a textos que desafiem seus acessos cognitivos, além de contribuir para um processo de desinformação pela informação, pode servir como estratégia de 
V. 11 (2)

1-20

maio-ago

2021

controle discursivo. Como observado nas análises acima, as agências de notícias, em sua maioria, reduzem questões complexas a poucos conceitos que elas direcionam como fundamentais para a compreensão de eventos reais. Essa estratégia episódico-textual pode limitar as experiências de inferenciação dos sujeitos, de forma a prejudicar não apenas suas habilidades de leitura e interpretação, mas também sua capacidade de construir memórias discursivas mais abrangentes.

Vivemos, na internet, experiências de leitura hipertextual. Segundo Xavier (2013b), essa configuração digital dos textos permitenos leituras múltiplas, não lineares e hiperconectadas. Pensamos que essa experiência de leitura em rede deve ser mais bem otimizada pelas agências de notícias. As publicações no Instagram, da forma como as encontramos configuradas, exploram o que acreditamos ser o processo de hiper-otimização da inferenciação e reduz as articulações de informações e interpretação dos sujeitos usuários.

Uma outra questão problemática discutida neste estudo se refere ao acesso. O texto jornalístico, de uma forma geral, é o resultado de formas de contingenciamento e acesso. No entanto, com as Tecnologias da Informação e Comunicação (TICs), as fronteiras de acesso podem ser rompidas. No caso em questão, isto é, o pronunciamento do atual presidente do Brasil, o acesso ao discurso na íntegra está disponível na plataforma do Governo Federal e no seu canal no YouTube. Isso implica que as agências de notícias podem utilizar os recursos hipertextuais para expandir a gama de acesso à informação de modo a promover formas de leituras mais amplas.

Doravante, a Teoria Social do Discurso esclarece que os sujeitos têm condições sociocognitivas de construírem sentidos a partir de sua experiência inferencial (FAIRCLOUGH, 2016; MARCUSCHI, 2011; AZEVEDO, 2008). E isso implica que as análises desenvolvidas neste trabalho não são deterministas, afinal, mesmo nos valendo de um dispositivo teórico semi-modular (Princípio Cognitivo da Relevância combinado com os princípios sociodiscursivos da Teoria Social do Discurso), o processo de compreensão é particularmente complexo e múltiplo. Ainda assim, pensamos que a relação texto, prática social e compreensão deve ser analisada a partir de implicações cognitivas, pragmáticas e discursivas.

Nesse sentido, a Teoria da Relevância, com os fundamentos de seu princípio cognitivo, pode nos ajudar a compreender como as produções enunciativas em postagens de redes sociais podem se valer das 
estratégias de otimização da informação para direcionar a compreensão dos leitores. Evidentemente, toda produção textual se basearia nesse processo, segundo o Princípio Cognitivo da Relevância. A questão central é o fato de algumas agências de notícias hiper-otimizarem, ou hipersimplificarem fatos noticiados. Assim, pensamos ser fundamental a discussão sobre o papel das práticas de leitura nas TICs.

\section{Referências}

AOS FATOS. 0 que é checagem de fatos - ou fact-checking? [S.1.] [2020?]. Disponível em: https://www.aosfatos.org/checagem-de-fatos-ou-factchecking/. Acesso em: 20 de jun. de 2020.

AZEVEDO, K. F. Manual de redação jornalística: o controle discursivo em tempos liberais. Anais da XX Jornada - GELNE - João Pessoa. João Pessoa: Anais da XX Jornada GELNE, 2004. 1293-1300. Disponível em: https://gelne. com.br/arquivos/anais/gelne-2004/prin total.htm Acesso em: 11 jun. 2020.

AZEVEDO, K. F. (Des)legitimação: ações discursivo-cognitivas para o processo de categorização social. 2008. F. 682. Tese (Doutorado) - Universidade Federal de Pernambuco, Departamento de Pós-Graduação em Letras. Recife, 2008. Disponível em: http://pgletras.com.br/2008/teses/tese-karina-falcone.pdf. Acesso em: 1 jun 2020.

BUZATO, M. E. K. Entre a Fronteira e Periferia: linguagem e letramento na inclusão digital. 2007. 285 f. Tese (Doutorado em Linguística Aplicada) Instituto de Estudos da Linguagem, Universidade Estadual de Campinas (IEL - Unicamp). Campinas, 2007. Disponível em: http://repositorio.unicamp.br/ jspui/bitstream/REPOSIP/269320/1/Buzato_MarceloElKhouri_D.pdf. Acesso em: 02 mar. 2020.

FAIRCLOUGH, N. Discurso e mudança social. Coordenação de tradução Izabel Magalhães. 2. ed. Brasília: Editora Universidade de Brasília, 2016.

FERREIRA, A. B. H. Aurélio século XXI: o dicionário da Língua Portuguesa. 5. ed. rev. e ampl. Rio de Janeiro: Nova Fronteira, 2020.

HARARI, Y. N. 21 lições para o século 21. Tradução de Paulo Geiser. 1. ed. São Paulo: Companhia das Letras, 2018.

MARCUSCHI, L. A. Compreensão textual como trabalho criativo. In: UNIVERSIDADE ESTADUAL PAULISTA. Prograd. Caderno de formação: formação de professores didática geral. V. 11. São Paulo: Cultura Acadêmica, 2011, p. 89-103. Disponível em: https://acervodigital.unesp.br/ handle/123456789/40358?mode=full Acesso em: 18 mai. 2020.

MELLO, P. C. A máquina do ódio: Notas de uma repórter sobre fake news e violência digital. São Paulo: Companhia das Letras, 2020.

RENÓ, D. Jornalismo Transmídia: a consolidação de um formato de notícias. In: IRIGARAY, F.; GOSCIOLA, V.; PIÑERO-ÓTERO, T. (org.). Dimensões 
V. $11(2)$ $1-20$ maio-ago 2021

Transmídia. Aveiro: Ria Editorial, 2019, p. 187-212. Disponível em: http:// www.riaeditorial.com/index.php/dimensoes-transmidia/. Acesso em: 06 jul. 2020.

SPERBER, D.; WILSON, D. Teoria da relevância. Tradução de Fábio José Rauen e Jane Rita Caetano da Silveira. Linguagem em (Dis)curso - LemD, Tubarão, v. 5, n. esp., 2005. pp. 221-268. Disponivel em: http://www.portaldeperiodicos. unisul.br/index.php/Linguagem_Discurso/article/view/287/301. Acesso em: 10 mar. 2020.

van DIJK, T. A. Cognição, discurso e interação. São Paulo: Contexto, 2010.

XAVIER, A. C. A era do hipertexto: Linguagem e Tecnologia. 2. ed. Recife: Pipa Comunicação, 2013a.

XAVIER, A. C. Retórica Digital: a língua e outras linguagens na comunicação mediada por computador. Recife: Pipa Comunicação, 2013b. Disponível em: https://www.pgletras.com.br/ documentos/acervo/ebooks/ebook-retoricadigital_Antonio-Carlos-Xavier.pdf. Acesso em: 10 mar. 2020. 